https://dx.doi.org/10.4314/jpb.v17i2.14

Vol. 17 no. 2, pp. 200-207 (September 2020)

http://ajol.info/index.php/jpb
Journal of PHARMACY AND BIORESOURCES

\title{
Assessment of the pharmaceutical equivalence and in vitro dissolution studies of amlodipine tablets marketed in Northern Nigeria
}

\author{
Ponjul DANDAM* and Jennifer D. AUDU-PETER \\ Department of Pharmaceutical Technology and Industrial Pharmacy, University of Jos, PMB 2084, Jos. Nigeria.
}

Received 28 $8^{\text {th }}$ July 2020; Accepted $31^{\text {st }}$ August 2020

\begin{abstract}
The extensive supply of poor quality and/or counterfeit drug products in many developing countries has made it vital to frequently carry out suitable tests to assess bioequivalence (BE) in a cost-effective manner. This study was intended to assess the pharmaceutical equivalence and dissolution profile of amlodipine $5 \mathrm{mg}$ tablets marketed in Jos and Kaduna metropolis. Ten brands of Amlodipine 5mg tablets were obtained from different community pharmacies and evaluated for different quality control parameters such as percent drug content, friability, hardness, thickness, weight uniformity, disintegration time, and dissolution. The results showed that brands F and I failed the test for percent drug content while the rest of the brands passed it. In addition, all the brands passed the disintegration and friability test while Brands C, F and I did not pass the hardness test. The dissolution profiles of all the brands were similar to the innovator brand at $\mathrm{pH} 6.8$, whereas at $\mathrm{pH} 1.2$, only four brands (B, E, H and I) had similar dissolution profile to the innovator. This study serves to justify for the assessment of in vitro parameters of commercially available amlodipine generics which may aid the prescribers' decision making.
\end{abstract}

Keywords: Amlodipine; Jos; Tablet properties, Dissolution profile

\section{INTRODUCTION}

Amlodipine is a dihydropyridine calcium channel blocker which inhibits the trans-membrane influx of calcium ions into vascular smooth muscle and cardiac muscle. It is weakly basic and has a pKa of 8.6. It is used to treat hypertension, chronic stable angina, and confirmed or suspected vaso-spastic angina [1]. The solubility of amlodipine has been improved by derivatization into various salt forms with amlodipine besylate (ADB) being the most commonly used in preparation of most dosage forms. Other salt forms that are known to be interchangeable with besylate include mesylate and maleate. The different salt forms affect the physicochemical properties of the amlodipine, for example, ADB salt is known to have better aqueous solubility compared to the amlodipine (AD) alone[2]. Amlodipine is available as tablet dosage form in doses of $5 \mathrm{mg}$ and $10 \mathrm{mg}$. Its drug to aqueous solvent $(\mathrm{D} / \mathrm{S})$ ratio is $\leq 250 \mathrm{ml}$ qualifying it to be of high solubility. It has an absolute bioavailability of $60-65 \%$ which would prevent it from being considered as high permeability drug molecule, but due to its high

*Correspondence. E-mail: ponjuldan@gmail.com Tel: +234-7035644025.

ISSN 0189-8442

(cc) BY-No 2020. Published by Faculty of Pharmaceutical Sciences, University of Jos, Nigeria. Under Creative Commons Attribution-NonCommercial 4.0 International License. https://creativecommons.org/licenses/by-nc/4.0/ 
metabolite excretion $(90-95 \%)$, it is categorized into high permeability API. Based on the high solubility and high permeability stated above, amlodipine therefore falls in class I of Biopharmaceutical Classification System (BCS) [3]. Generic drugs are medicines with expired patent of the active drug molecule and may even include the originator product. This means that the generics can be marketed as branded products with the trade name belonging to the manufacturer[4].

Generic substitution is the process of dispensing a brand in the place of another prescribed brand which is pharmaceutically equivalent (drug products in identical dosage forms, same active ingredients, use the same route of administration, and have same strength or concentration). This practice, justified by the principle that, the generics should exhibit the same clinical safety and efficacy as predicted by the in vitro dissolution studies used as a gateway for the product to reach the market. Although the primary goal of generics is price reduction and affordability of medicines, many counterfeit generics have been reported to pervade the market, hence affecting the quality of health care[5]. The menace of drug counterfeiting has hampered the trust of generics and the practice of pharmaceutical substitution in Nigeria. This therefore calls for pharmaceutical equivalence studies to authenticate the different sources of medicines and provide the prescribers and dispensers with information on product quality in terms of bioavailability for supporting their choice.

Dissolution plays a key role in defining bioavailability of the solid dosage forms especially those containing drug substances of low aqueous solubility. It is therefore an integral part of physicochemical characterization of active pharmaceutical ingredients (APIs) in drug product formulation. It also forms the basis for prediction of in vivo bioavailability from the concept of in vivo-in vitro correlation[6]. The correlation between invitro dissolution and in vivo bioavailability has also been demonstrated in a precious study [7]. The Dissolution of a solid dosage form is affected by the type and ratio of excipients, processing factors (methods of granulation and the compression force applied [8]. An in vitro dissolution test helps in formulation development, investigations for post-approval changes, quality control and post marketing surveillance [9]. Drug dissolution, a key factor in the success of therapeutic outcome of drug product, is a rate kinetic process that deals with how long it takes a solute to form a saturated solution. This is a crucial parameter to the overall therapeutic process, since the effectiveness of a tablet hinges on its rate of dissolution within the gastrointestinal tract (GIT) prior to absorption into the systemic circulation[10]. Due to adverse conditions prevalent in the retail outlets for pharmaceutical products, in vitro quality control tests are basic necessity to predict the bioavailability through the assessment of the tablet properties $[11,12]$. It is also necessary to note the organoleptic properties such as colour, taste and odour. Package information on drug products provide useful information to regulatory agencies as well as users about the origin of the product, among other vital information [13].

In this study, the pharmaceutical equivalence of ten different brands of Amlodipine Besylate $(5 \mathrm{mg})$ tablets were investigated. The dissolution profiles of the brands under biowaiver conditions was also evaluated.

\section{EXPERIMENTAL}

Ten different brands of commercial Amlodipine Besylate $5 \mathrm{mg}$ tablets were purchased from local retail pharmacies in Jos and Kaduna metropolises and coded as A, B, $\mathrm{C}, \mathrm{D}, \mathrm{E}$ to J. Among them was the innovator brand (brand D). The physical evaluations were performed as described by USP 36 procedures, Audu-Peter \& Ekoja [10] and 
Kuribayashi et al [11].Tablets were subjected to various physical tests which included weight variation (Gallenkamp Mettler Balance P165, England), thickness (Venier caliper), hardness (Monsanto hardness tester) and friability (Type TA3R, Erweka, Germany). The disintegration test was carried out by using Type ZT3, Erweka, Germany for which six tablets of each brand were subjected to $900 \mathrm{ml}$ of distilled water that was maintained at $37 \pm 2{ }^{\circ} \mathrm{C}$. The mean and standard deviation for each of the test results were gotten through statistical analyses. Content assay was carried out according to the method by Mahwish et. al.,[14]with twenty tablets randomly selected per brand. The tablets were crushed into a powder and a weight equivalent to one tablet $(5 \mathrm{mg})$ was weighed, dissolved in methanol and filtered. The volume of the filtrate was made up to $100 \mathrm{ml}$ using water. The absorbance of solutions was measured using a UVSpectrophotometer (Metertech, SP 8001, Taiwan). The concentration of the solution was calculated from a previously established calibration plot of the reference standard $(\mathrm{y}=$ $\left.21.2 \mathrm{x}+0.0036, \mathrm{R}^{2}=0.9907\right)$ after which the quantity $(\mathrm{mg})$ and percentage content of the drug in the tablet was determined.

In vitro dissolution studies were carried out using USP apparatus type II, at $75 \mathrm{rpm}$ (Hanson Research Corporation SR-6 Chatsworth, California) with six replicates. Dissolution media of $900 \mathrm{ml}$ each of $0.1 \mathrm{~N} \mathrm{HCl}$ and Phosphate buffer at $\mathrm{pH} 1.2$ and 6.8 and at a temperature of $37^{\circ} \mathrm{C}$ was used for the study where $5 \mathrm{ml}$ aliquots were withdrawn and replaced with same volume of buffer at 5, 10, 15, 30, 45 and 60-minute intervals. The procedure was carried out three times for each brand after which the average was determined. The samples were then filtered and the absorbance measured using UV Spectrophotometer (Metertech, SP 8001, Taiwan) at $239 \mathrm{~nm}$. The release profiles of the brands were determined from the graph (percent release Vs Time) which was plotted using MS Word, and the result was reported. The validation process was according to the guidelines contained in USP 32 [15]. A model independent approach as recommended by US FDA guidance for dissolution data equivalence involving use of similarity factor $\left(\mathrm{f}_{2}\right)$ and difference factor $\left(f_{1}\right)$ was adopted for comparing the dissolution profiles of different test brands in reference to the innovator brand [16]. The dissolution results were analysed using the similarity factor $\left(f_{2}\right)$, difference factor $\left(f_{1}\right)$ and the dissolution efficiency (DE). The similarity factor $\left(f_{2}\right)$ is a logarithmic reciprocal square root transformation of the sum of squared error and is a measurement of the similarity in the dissolution (\%) of two curves:

$f_{2}=50 \times \log \left\{\left[1+\frac{1}{n} \sum_{j=1}^{n}\left(R_{j}-T_{j}\right)^{2}\right]^{-0.5} \times 100\right\}$

where $n$ is the number of dissolution sample times and $R_{j}$ and $T_{j}$ are the individual or mean percents dissolved at each time point for the reference and test products respectively.

The difference factor can also be calculated using the equation below:

$f_{1}=\frac{\sum_{j=1}^{n}\left(R_{j}-T_{j}\right)}{\sum_{j=1}^{n} R_{j}} \times 100$ Eqn 2

where $\mathrm{Rj}$ and $\mathrm{Tj}$ are the percentage release of reference and test brands respectively.

The dissolution efficiency (DE) of a pharmaceutical dosage form is the area under the dissolution curve up to a certain time, $t$, expressed as a percentage of the area of the trapezium described by $100 \%$ dissolution in the same time [17].

$$
\text { D. } E=\frac{\int_{0}^{t} y \times d t}{y_{100} \times t} \times 100 \%
$$
.Eqn 3

According to the FDA guidance, $\mathrm{f}_{2}$ values from $50-100 \%$ ensure similarity and f1 values less than $50 \%$ ensure the dissimilarity of two dissolution profiles. The dissolution profiles may be established as comparable without additional mathematical estimation when drug dissolution is more than $85 \%$ within 15 minutes [14]. 


\section{RESULTS}

The results of the visual inspection of the tablet packaging and properties are shown in Table 1. It can be seen from the table that one of the brands was not registered with the regulatory authority (NAFDAC). The table also shows that all the brands were within their expiry dates.

The organoleptic properties of the various brands are shown in Table 2 . It can be seen that all the brands are white in color, have a dull lustre and a smooth surface texture. All the brands are circular in shape except Brand $\mathrm{D}$ which is octagonal.

The physico-chemical test results are shown in Table 3 and it can be seen that brands $\mathrm{C}, \mathrm{F}$ and I failed the hardness test while all the brands passed the test for disintegration and friability. Additionally, brands F and I failed the content assay while all other brands passed. The release characteristics of the brands in different media ( $\mathrm{pH} 1.2$ and $\mathrm{pH}$ 6.8) are shown in Fig. 1 and 2. The dissolution efficiency, $\mathrm{f}_{1}$ and $\mathrm{f}_{2}$ factors are presented in Table 4. It shows that all the tested brands exhibited similar dissolution profiles with the innovator at $\mathrm{pH} 6.8$, whereas only four brands $(\mathrm{B}, \mathrm{E}, \mathrm{H}$ and I) were similar to the innovator at $\mathrm{pH}$ 1.2.

\section{DISCUSSION}

Most of the brands had all the information which is required on a pharmaceutical product including batch number, manufacturing and expiry dates, evidence of regulatory certification etc. as shown in Table 1 . However, brand $\mathrm{J}$ from UK had no NAFDAC registration number. This means that brand $\mathrm{J}$ did not have both regulatory and legal approval for entry into the country, it is most likely illegally imported and marketed. From the results presented in Table 2, all the brands were white in color with dull luster and smooth texture. All had a circular shape except the innovator brand D which was octagonal. Half of the brands had inscriptions while the other half were plain without any writing.

Table 1: Label information of the various brands of amlodipine $(5 \mathrm{mg})$ tablets evaluated

\begin{tabular}{llllll}
\hline Brand & Country of Origin & Batch No. & Man. Date & Expiry Date & NAFDAC Reg No. \\
\hline A & India & 5797066 & June, 2017 & May, 2020 & B4-6506 \\
B & India & PV17001 & May, 2017 & April, 2020 & B4-0516 \\
C & India & A18401 & June, 2018 & June. 2021 & B4-6763 \\
D & Germany & F10047637 & Aug, 2015 & July, 2019 & $04-1386$ \\
E & India & $830578 B$ & June, 2018 & May, 2021 & A4-2110 \\
F & China & 171205 & Dec, 2017 & Dec, 2020 & B4-7199 \\
G & India & AVU1601 & Sep, 2016 & Aug, 2019 & A4-2280 \\
H & China & 161115 & Nov, 2016 & Nov, 2019 & A4, 7894 \\
I & India & 8094 & Mar, 2018 & Feb, 2021 & B4-0430 \\
J & United Kingdom & 0540917 & May, 18 & Sep, 2022 & nil \\
\hline
\end{tabular}

Table 2: Organoleptic properties of various brands evaluated

\begin{tabular}{lllllc}
\hline Brand & Color & Shape & Inscription & Luster & Surface Texture \\
\hline A & White & Circular & - & Dull & Smooth \\
B & White & Circular & - & Dull & Smooth \\
C & White & Circular & - & Dull & Smooth \\
D & White & Octagonal & Pfizer/Aml-5 & Dull & Smooth \\
E & White & Circular & AM5 & Dull & Smooth \\
F & White & Circular & - & Dull & Smooth \\
G & White & Circular & A5 & Dull & Smooth \\
H & White & Circular & A5 & Dull & Smooth \\
I & White & Circular & - & Dull & Smooth \\
J & White & Circular & A5 & Dull & Smooth \\
\hline
\end{tabular}


Table 3: Physicochemical properties of the amlodipine brands

\begin{tabular}{lllllcl}
\hline Brand & $\begin{array}{l}\text { Weight } \\
\text { Uniformity } \\
(\mathrm{g} \pm \mathrm{SD})\end{array}$ & $\begin{array}{l}\text { Drug } \\
\text { Content } \\
(\%)\end{array}$ & $\begin{array}{l}\text { Thickness } \\
(\mathrm{mm} \pm \mathrm{SD})\end{array}$ & $\begin{array}{l}\text { Friability } \\
(\%)\end{array}$ & $\begin{array}{c}\text { Disintegration } \\
(\mathrm{s})\end{array}$ & $\begin{array}{l}\text { Hardness } \\
(\mathrm{KgF})\end{array}$ \\
\hline $\mathrm{A}$ & $0.342 \pm 0.003$ & 85.283 & $3.407 \pm 0.084$ & 0.321 & 18 & $4.667 \pm 0.724$ \\
$\mathrm{~B}$ & $0.200 \pm 0.001$ & 97.547 & $3.214 \pm 0.011$ & 0.320 & 15 & $6.000 \pm 0.926$ \\
$\mathrm{C}$ & $0.210 \pm 0.008$ & 90 & $3.797 \pm 0.026$ & 0.611 & 42 & $2.600 \pm 0.632$ \\
$\mathrm{D}$ & $0.203 \pm 0.001$ & 101.321 & $2.926 \pm 0.005$ & 0.015 & 18 & $4.533 \pm 0.516$ \\
$\mathrm{E}$ & $0.13 \pm 0.020$ & 108.868 & $2.409 \pm 0.01$ & 0.837 & 55 & $4.467 \pm 0.516$ \\
$\mathrm{~F}$ & $0.185 \pm 0.005$ & 79.623 & $3.567 \pm 0.061$ & 0.951 & 12 & $3.733 \pm 0.458$ \\
$\mathrm{G}$ & $0.125 \pm 0.001$ & 99.434 & $3.073 \pm 0.237$ & 0.593 & 44 & $5.533 \pm 0.640$ \\
$\mathrm{H}$ & $0.244 \pm 0.006$ & 90 & $3.963 \pm 0.040$ & 0.450 & 58 & $4.000 \pm 000$ \\
$\mathrm{I}$ & $0.430 \pm 0.013$ & 83.396 & $3.703 \pm 0.057$ & 0.772 & 11 & $3.800 \pm 0.560$ \\
$\mathrm{~J}$ & $0.203 \pm 0.002$ & 95.660 & $3.345 \pm 0.033$ & 0.686 & 11 & $5.733 \pm 0.704$ \\
\hline
\end{tabular}

Table 4: Dissolution Efficiency $\left(\mathrm{DE}_{30}\right)$, Dissimilarity $\left(\mathrm{f}_{1}\right)$ and Similarity $\left(\mathrm{f}_{2}\right)$ factors at $\mathrm{pH} 1.2$ and 6.8

\begin{tabular}{lllllll}
\hline \multirow{2}{*}{ Brand } & \multicolumn{2}{c}{$\mathrm{DE}_{30}(\%)$} & \multicolumn{2}{c}{$\mathrm{f}_{1}(\%)$} & \multicolumn{2}{c}{$\mathrm{f}_{2}$} \\
\cline { 2 - 7 } & $\mathrm{pH} \mathrm{1.2}$ & $\mathrm{pH} 6.8$ & $\mathrm{pH} 1.2$ & $\mathrm{pH} \mathrm{6.8}$ & $\mathrm{pH} 1.2$ & $\mathrm{pH} 6.8$ \\
\hline $\mathrm{A}$ & 69.445 & 67.630 & 16.424 & 5.123 & 41.048 & 66.782 \\
$\mathrm{~B}$ & 69.828 & 69.863 & 4.074 & 4.291 & 62.195 & 51.943 \\
$\mathrm{C}$ & 63.391 & 68.729 & 41.442 & 6.733 & 3.517 & 59.354 \\
$\mathrm{D}$ & 69.682 & 75.421 & \multicolumn{4}{c}{ Reference } \\
$\mathrm{E}$ & 69.420 & 67.456 & 5.265 & 0.271 & 56.343 & 87.5 \\
$\mathrm{~F}$ & 71.080 & 67.986 & 12.106 & 8.083 & 47.231 & 57.037 \\
$\mathrm{G}$ & 68.251 & 67.830 & 12.713 & 7.276 & 45.021 & 59.451 \\
$\mathrm{H}$ & 71.981 & 68.257 & 4.048 & 3.498 & 54.608 & 55.945 \\
$\mathrm{I}$ & 71.082 & 68.580 & 8.339 & 3.496 & 53.374 & 57.603 \\
$\mathrm{~J}$ & 68.211 & 67.303 & 10.799 & 1.237 & 43.945 & 83.653 \\
\hline
\end{tabular}

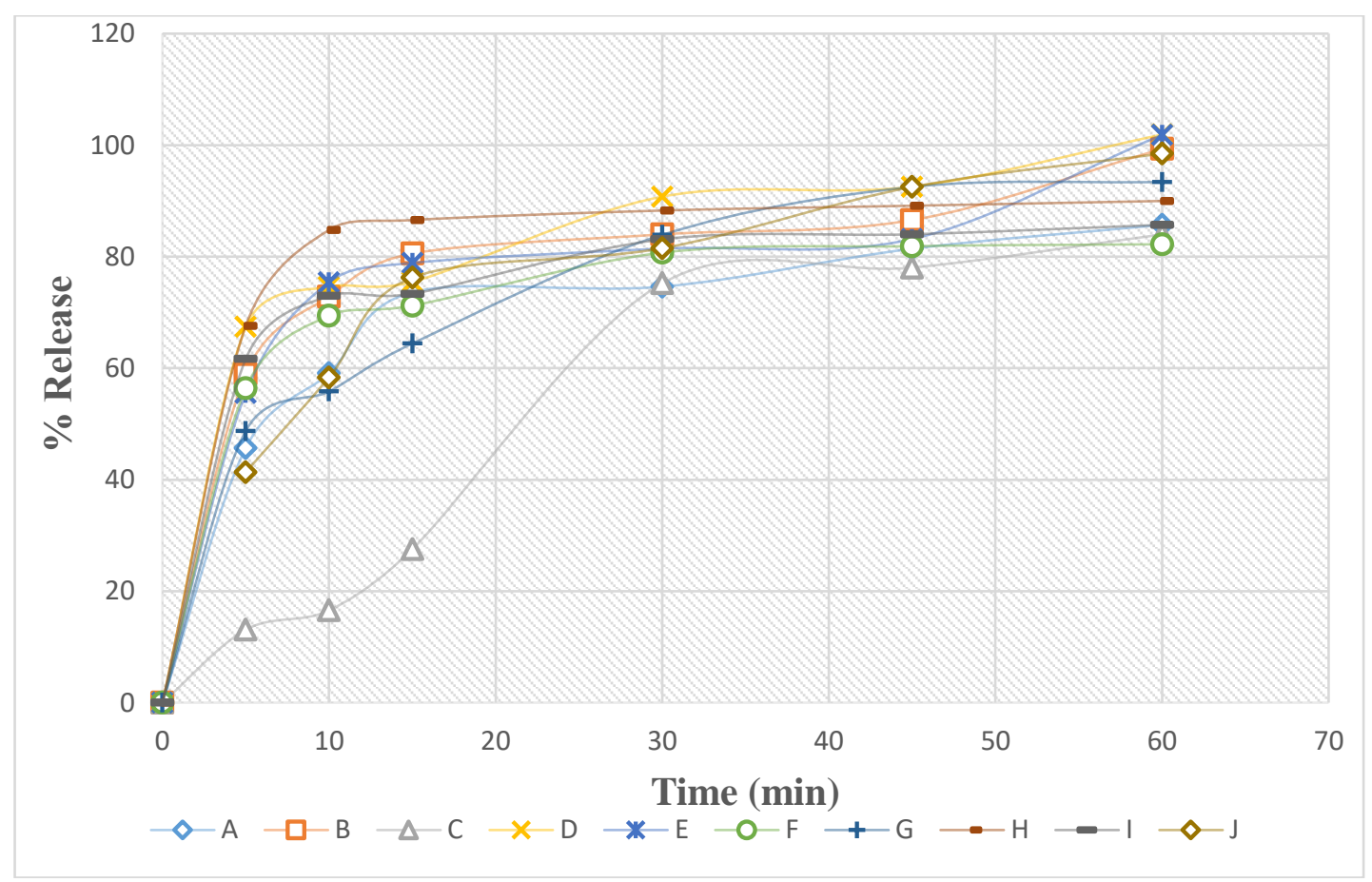

Figure 1: Dissolution profile for the various brands at $\mathrm{pH} 1.2$ 
P. Dandam \& J.D. Audu-Peter/J. Pharmacy \& Bioresources 17(2), 200-207 (2020)

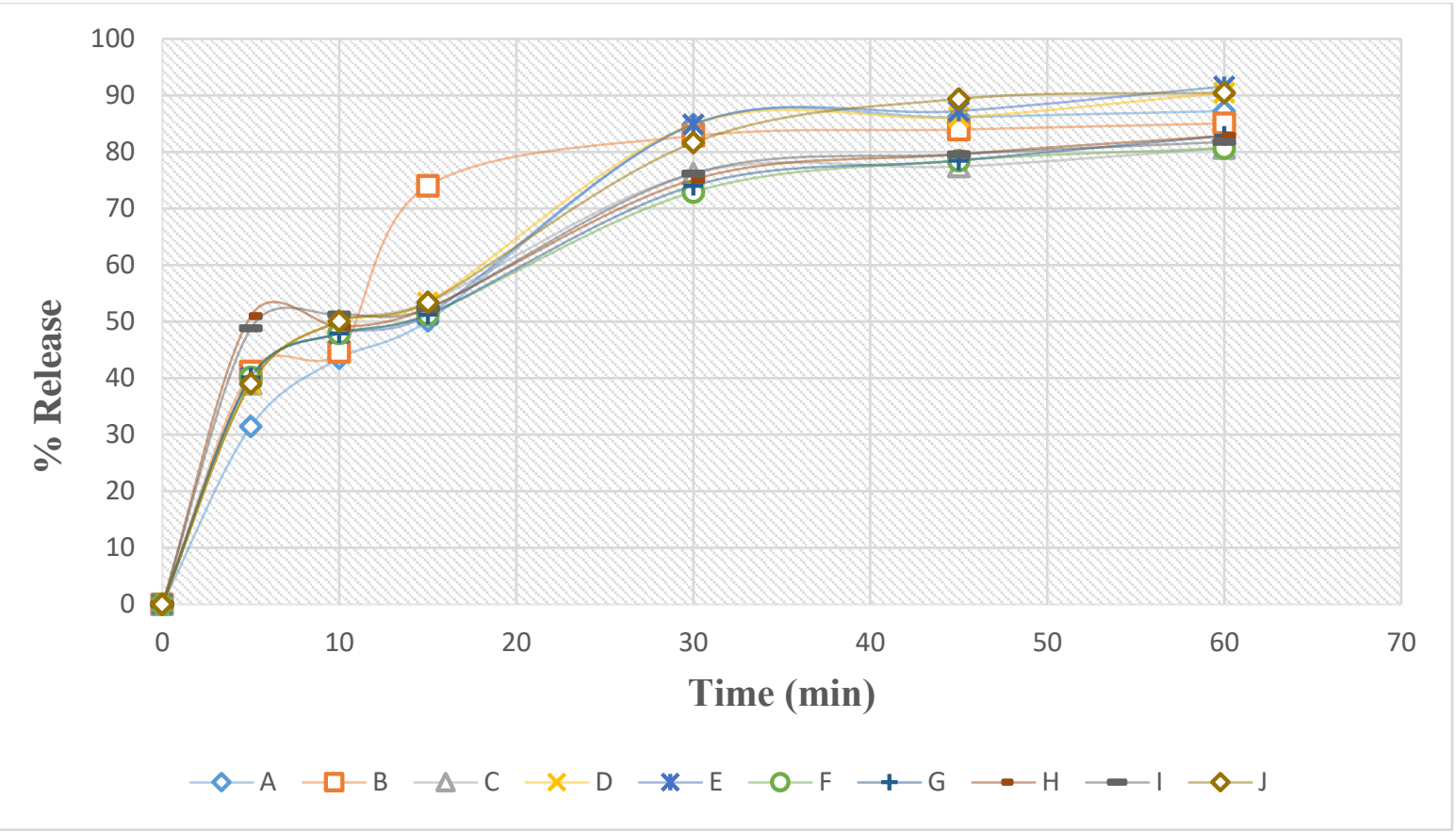

Figure 2: Dissolution profile of various brands at $\mathrm{pH} 6.8$

The shape, color and inscriptions are commonly used for identification purposes. The shape and color are primarily used for physical identification of the dosage form while the inscriptions are written specifically to identify the tablet with the manufacturer [18].

The results of the physical properties of the brands as presented in Table 3 shows that all the brands passed the weight uniformity test since they all complied with USP 36 specifications which specifies that tablets weighing $130 \mathrm{mg}$ or less should not deviate by $\pm 10 \%$ and all the brands had values within the limits [19].

The disintegration test is a preliminary test to predict the release of the drug from the medicine (dosage form). According to BP, a well formulated and manufactured immediate release tablet dosage form should disintegrate within $15 \mathrm{~min}$ while the USP specifies $30 \mathrm{~min}$. Based on these pharmacopoeial requirements, all the brands under investigation passed the test for disintegration and are expected to readily release the drug once administered to a patient.
The drug content analysis determines whether the tablet batch contains the stated amount of the active ingredient. According to the USP, the amount of drug in each tablet should lie in the range of $85 \%-115 \%$. Based on this specification, brands $\mathrm{F}$ and I failed the test for assay while the rest of the brands passed it. This indicates that the two brands ( $F$ and I) do not comply with specifications of good manufacturing practices

The friability is an unofficial test designed to ascertain the ability of the tablets to withstand mechanical breakage due to vibrations associated with transportation and carriage. As a requirement, the friability for a quality tablet should be $\leq 1 \%$. Our findings demonstrate that all the brands of amlodipine studied passed, with the innovator (D) having the lowest friability of $0.015 \%$ and brand $\mathrm{F}$ with the highest friability of $0.951 \%$. Another measure of tablet resistance to mechanical breakage is hardness test. To withstand mechanical shocks during handling in manufacture, packing, shipping and handling by retailers, a good tablet should have a hardness of $4 \mathrm{~kg} / \mathrm{cm}^{2}$. According to our results, 
three brands ( $\mathrm{C}, \mathrm{F}$ and $\mathrm{I})$ had low values while the rest possessed good mechanical strength including the innovator product. . Low hardness is attributed to a low compression force, low binder concentration or insufficient volume of granulating fluid [20].

The release characteristics of the brands in different media $(\mathrm{pH} 1.2$ and $\mathrm{pH}$ 6.8) are shown in Fig. 1 and 2 while the dissolution efficiency, $\mathrm{f}_{1}$ and $\mathrm{f}_{2}$ factors are presented in Table 4. The dissolution is a key parameter for clinical interchangeability of brands since it predicts the bioavailability of the drug. Therefore, brands showing similar dissolution profiles can be regarded as bioequivalent and can be interchanged in the absence of the other. According to WHO, to meet biowaver condition for class 1 Active Pharmaceutical Ingredient (API), more than $85 \%$ dissolution of the labelled amount is required within $30 \mathrm{~min}$ in standard media at $\mathrm{pH} 1.2$ and 6.8 using the paddle apparatus at $75 \mathrm{rpm}$ or the basket apparatus at $100 \mathrm{rpm}$. Based on the WHO biowaiver condition, $80 \%$ of products investigated did not meet the criteria including the innovator (D). Precisely, only two brands (innovator $\mathrm{D}$ and $\mathrm{H}$ ) had more than $85 \%$ of the active content release within $30 \mathrm{~min}$. This is in contrast to other studies carried out in Russia[21] and Pakistan [14] whereby $100 \%$ of the generic brands which were tested met the Biowaiver conditions.

Furthermore, the dissolution profiles were analysed using the similarity $\left(f_{2}\right)$ and difference factors $\left(f_{1}\right)$ in comparison to the innovator product $\mathrm{D}$. According to these factors, two brands are considered similar if $\mathrm{f}_{2}$ $>50$ and $\mathrm{f}_{1}<15$ [22]. Therefore, as shown in table 4 , the dissolution profiles of all the brands are similar to the innovator brand at $\mathrm{pH} 6.8$, whereas at $\mathrm{pH} 1.2$, only four brands $(\mathrm{B}, \mathrm{E}, \mathrm{H}$ and I) had similar dissolution profile to the innovator. But using the $\mathrm{f}_{1}$ factor alone, only brands $F, G$ and $J$ can be considered to be bioequivalent to the innovator. This result is in contrast to other studies which Although brands $\mathrm{F}$ and I had similar dissolution profiles as the innovator at $\mathrm{pH} 6.8$, they failed the content uniformity test and thus may not be considered as pharmaceutical equivalents with the innovator brand.

Conclusion. The presented data shows that all the brands passed the physical tests while two brands failed in the content uniformity test. Also, the brand that did not have National Agency for Food and Drug Administration and Control (NAFDAC) registration number, was seen to pass all the test and can also be said to be comparable with the innovator brand in terms of the in vitro dissolution test. It is clear to see that not all generic drugs in the market meet up to the required specifications and it is thus important to regularly carry out post marketing product assessment in order to ascertain the quality of drug products being sold in the Nigerian market. Additionally, it is necessary for all prescribers and pharmacists to have adequate information on interchangeability for the substitution of drugs.

\section{REFERENCES}

1. Amlodipine besylate prescribing information and Norvasc $®$ Product Monograph, Pfizer, 2006.

2. Sheraz, M.A., Ahsan, S.F., Khan, M.F., Ahmed, S., \& Iqbal, A. Formulations of Amlodipine: A Review. Journal of Pharmaceutic, vol. 2016, Article ID 8961621, 1-11, 2016. http://dx.doi.org/10.1155/2016/8961621.

3. Akinleye, M.O., Oyetunde, O.O., Okpara, H.E \& Ayerota, E.L. Equivalence of two Generic Brands of Amlodipine Besylate under Biowaiver Conditions. International Journal of Pharmacy and Pharmaceutical Sciences.2011; 4(2):265-268.

4. Lofgren, H. Generic Drugs: International Trends and Policy Developments in Australia. Aust Health Rev.: a publication of the Australian Hospital Association. 2004;27(1):39-48.

5. Ubajaka, C. F., Obi-Okaro, A. C., Emelumadu, O. F., Azumarah, M. N., Ukegbu, A. U \& Ilikannu, S. O. Factors Associated with Drug Counterfeit in Nigeria: A Twelve Year Review. BJMMR. 2015; 12(4): 1-8.

6. Dyas, M.A, Ford, J.L. Dissolution and Dissolution Testing. In: Swarbrick J, ed. Encyclopedia of 
Pharmaceutical Science and Technology. 4th ed. Boca Raton, FL: CRC Press; 2013.

7. Helgi, J.C., Lourdes, M.C. and María Elena, G.C. (2017). Comparative in vitro dissolution and in vivo bioavailability of commercial amlodipine tablets. Tropical Journal of Pharmaceutical Research, September 2018; 17(9): 1685-1691.

8. Audu-Peter, J.D. and Ibrahim, M.A. Interaction of Binder, Disintegrant and Compression Pressure in Tablets 1: Effect of Binder Efficiency. Nigerian Journal of Pharmaceutical Research. 2014; 10(1):4756.

9. Shaikh F., Patel V., Patel M., Surti N. Dissolution Method Development and Validation for Lercanidipine Hydrochloride Tablets. Dissolution technologies [Internet]. 2018 [cited 2020 Mar 20]. Available from:

https://www.researchgate.net/publication/323527427 _Dissolution_

Method_Development_and_Validation_for_Lercanid ipine_Hydrochloride_Tablets/dx.doi.org/10.14227 /DT250118P38.

10. Audu-Peter, J.D, Ekoja, A. In Vitro Assessment of Six Brands Of Glibenclamide Tablets Marketed In Jos Metropolis. Journal of Pharmaceutical and Allied Sciences. 2018; 15(3): $2864-2873$.

11. Kuribayashi, K., Takabatake, T., Mizuno, K. Effects of Storage Conditions on Dissolution Rates of Indomethacin Capsules. Chem. Pharm. Bull. 2018; 66 (8): 779-784.

12. Komal, C., Dhara, B., Sandeep, S., Shantanu, D. Priti, M.J. Dissolution-Controlled Salt of Pramipexole for Parenteral Administration: In Vitro Assessment and Mathematical Modeling. Dissolution Technologies [Internet]. 2019; 26: 28-35. Available from:

https://www.researchgate.net/publication/331426737 DissolutionControlled_Salt_of_Pramipexole_for_Par enteral_Administration_In_Vitro_Assessment_and_ Mathematical_Modeling/citation/download/ dx.doi.org/10.14227/DT 260119P28.

13. Audu-Peter, J. D; Ochekpe, N. A. and Kemas, U.C. Assessment of Impurities in Pharmaceutical Solid Dosage Forms Using Thin Layer Chromatography (TLC). Journal of Pharmaceutical and Allied Sciences. 2015; 12 ( 2): 2248 - 2257.
14. Mahwish, F., Nighat, R., Sana, G., Fakhsheena, A., Lubna, G., Saeed, A.S. (2014). Assessment of Pharmaceutical Quality Control and Equivalence of Various Brands of Amlodipine Besylate (5 Mg) Tablets Available in the Pakistani Market Under Biowaiver Conditions . International Journal of Pharmacy Pharmaceutical Sciences. 2014; 6(2).

15. United States Pharmacopoeia USP32-NF27. <1092> The Dissolution Procedure: Development And Validation. Pp 599.

16. Fukuda, H., Hiramatsu, K. Primary targets of fluoroquinolones in Streptococcus pneumoniae. Antimicrob Agents and Chemotherapy. 1999; 43: 410-412.

17. Islam, S.M.A, Islam, S., Shahriar, M., Dewan, I. Comparative in vitro dissolution study of Aceclofenac Marketed Tablets in Two Different Dissolution Media by Validated Analytical Method. Journal of Applied Pharmaceutical Science. 2011; 01 (09): 87-92.

18. Eichie, E. F., Arhewoh, M. I., Isesele, J. E., \& Olatunji, K. T (2011). In Vitro Assessment of Quality Control Parameters of Some Commercially Available Generics of Amlodipine Besylate in Nigerian Drug Market. International Journal of Health Research.2014; 4(1): 57-61.

19. United States Pharmacopoeia (USP) 36/NF 31 (2013). <905> Uniformity of Dosage Unit, Weight Variation, Content Uniformity. Vol 1.Rockville: United States Pharmacopoeia Convention,. ISBN: 978-1-936424-12-2. 4. Pp431-2.

$20 . \quad$ Ibezim, E.C., Attama, A.A., Obitte, N.C., Onyishi, V.I., Brown ,S.A. In vitro prediction of in vivo bioavailability and bioequivalence of brands of metronidazole tablets in Eastern Nigerian drug market. Scientific Research and Essay. 2008; 3(11), 552-558.

21. Shohin, I.E., Ramenskaya, G.V. Vasilenko, G.F \& Malashenko, E.A. In Vitro Dissolution Kinetics of Amlodipine Tablets Marketed in Russia Under Biowaiver Conditions. Dissolution Tech. 2010. dx.doi.org/10.14227/DT170310P20.

22. Zaid, A. N., Shraim, N., Radwan, A., Jaradat, N., Hirzallah, S., \& Issa, I (2017). Does GastroPlus Support Similarity and Dissimilarity Factors of in vitro-in vivo Prediction in Biowaiver Studies? A Lower Strength Amlodipine as a Model Drug. Drug Reserch.2010;68(2), 1-7. 